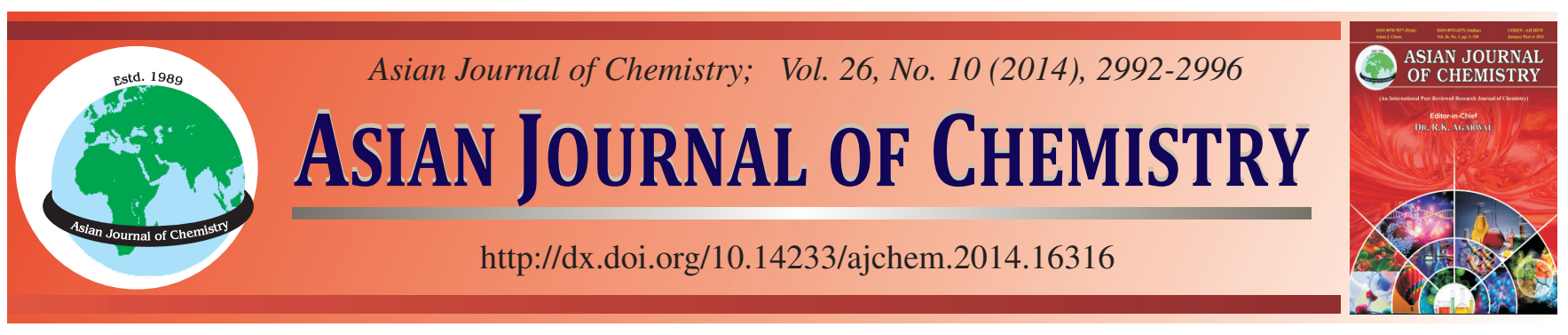

\title{
Extractive Spectrophotometric Method for Determination of Anti-Viral Drug Ribavirin Using Eriochrome Black-T
}

\author{
Nawal A. Alarfas ${ }^{1, *}$, Reda A. Ammar ${ }^{1,2}$ and Maha F. El-Tohamy ${ }^{1}$
}

${ }^{1}$ Deparartment of Chemistry, College of Science, King Saud University P.O. Box 22452, Riyadh 11495, Saudi Arabia

${ }^{2}$ Deparartment of Chemistry, College of Science, Al-Azhar University, Cairo, Egypt

*Corresponding author: Tel/Fax: +966 14772245; E-mail: nalarfaj@ hotmail.com

A new extractive spectrophotometric method for determination of anti-viral drug ribavirin was developed and validated. The proposed method was based on the formation of red colored complex with Eriochrome black-T in acidic medium. The absorbance of extractive organic layer with chloroform was measured at $576 \mathrm{~nm}$. Beer's law was obeyed revealed that the linear concentration range was 2-120 $\mu \mathrm{g} / \mathrm{mL}(\mathrm{r}=0.999)$ with lower detection and quantification limits 0.87 and $1.76 \mu \mathrm{g} / \mathrm{mL}$, respectively. The proposed method was validated according to $(\mathrm{ICH})$ guidelines and successfully applied for the determination of the drug in bulk powder and pharmaceutical formulations.

Keywords: Ribavirin, Eriochrome black-T, Spectrophotometric method, Ion-pair complexation.

\section{INTRODUCTION}

Ribavirin (1-b-D-ribofuranosyl-1H-1,2,4-triazole-3carboxamide (Fig. 1) is an anti-viral drug indicated for severe respiratory syncytial virus infection and used in conjugation with interferon $\alpha-2 b$ or interferon $\alpha-2 a$ in the treatment of hepatitis $\mathrm{C}$. It is considered by some physicians to be an effective and sometimes life-saving drug, but studies have also indicated that the drug may pose a reproductive risk to health care workers ${ }^{1}$. A literature survey showed that several methods have been reported for the determination of ribavirin including high performance liquid chromatography ${ }^{2,3}$, liquid chromatography-mass spectrometry ${ }^{4-7}$, thin layer chromatography ${ }^{8}$, capillary electrophoresis ${ }^{9}$, spectrophotometry ${ }^{10-12}$ and spectrofluorimetry ${ }^{12-14}$.

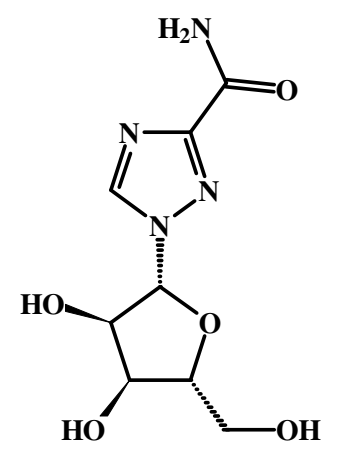

Fig. 1. Structure of ribavirin
Eriochrome black-T, 3-hydroxy-4-[1-hydroxy-2naphthalenyl) azo]-nitro-1-naphthylene sulfonic acid mono sodium salt (Fig. 2), is a complexometric indicator which commonly used in complexometric titrations. The literature survey clarified that several methods have been reported for determination of metal ions such as $\mathrm{Ca}^{2+}, \mathrm{Mg}^{2+}, \mathrm{Ni}^{2+}$ and $\mathrm{Cu}^{2+}$ using Eriochrome black-T $\mathrm{T}^{15-18}$. Also Eriochrome black-T was used for determination of several pharmaceutical species such as tramadol hydrochloride ${ }^{19}$, drotaverine hydrochloride ${ }^{20}$, fluoroquinolones antibacterial agents such as ofloxacin, lomefloxacin and enorfloxacin ${ }^{21}$, anti-histaminic agent promethiazine hydrochloride ${ }^{22}$ and antihypertensive drug nifedipine ${ }^{23}$.

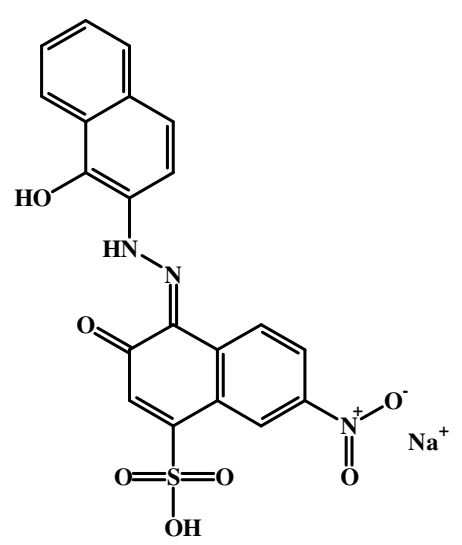

Fig. 2. Structure of Eriochrome black-T 
In the present study, a new spectrophotometric method is developed for the determination of antiviral drug ribavirin based on the complex formation between the drug and Eriochrome black-T.

\section{EXPERIMENTAL}

All chemicals and reagents were of analytical grade and distilled water was used throughout the experimental procedures. Pure grade ribavirin was kindly supplied from T3A Co., Egypt. The pharmaceutical preparation (Rebetol® 200 $\mathrm{mg} /$ capsule Schering-Plough Company, USA) was purchased from local drug stores. Nitric acid (purity $70 \%$ ), hydrochloric acid (purity $37 \%$ ) and acetic acid (purity $99.7 \%$ ) were purchased from Sigma-Aldrich (Germany). Chloroform (purity $99 \%$ ), benzene (purity $99 \%$ ), methanol (purity $99.8 \%$ ), diethyl ether (purity 99.7\%), dichloromethane (purity 99.9\%) and toluene (purity $99.8 \%$ ) were purchased from $\mathrm{BDH}$ laboratory supplies (England). Eriochrome black-T was obtained from Fine LTD (India).

Ultrospec-2100 pro, UV-visible spectrophotometer with matched $1 \mathrm{~cm}$ quartz cells was used for all spectrophotometric measurements. HANNA pH meter (Romania) was used for $\mathrm{pH}$ adjustments.

Standard drug solution: Stock solution of ribavirin was prepared by dissolving $15 \mathrm{mg}$ of the drug in $100 \mathrm{~mL}$ of distilled water. Further dilutions $(2-120 \mu \mathrm{g} / \mathrm{mL})$ were done with the same solvent as appropriate. The standard solution was stable for two weeks when kept in the refrigerator.

Standard Eriochrome black-T solution: The standard Eriochrome black-T solution, $0.2 \%$ (w/v) was prepared in $10 \mathrm{~mL}$ methanol then completed to $100 \mathrm{~mL}$ using distilled water.

Procedure for calibration graph: Aliquots of ribavirin stock solution (equivalent to $2-120 \mu \mathrm{g} / \mathrm{mL}$ of the drug) were transferred into a series of $100-\mathrm{mL}$ separating funnels. $0.5 \mathrm{~mL}$ of $0.2(\mathrm{w} / \mathrm{v})$ Eriochrome black-T was added followed by 1.5 $\mathrm{mL}$ of $5 \mathrm{~mol} / \mathrm{L}$ acetic acid. The separating funnels were vigorously shacking and the ion pair complex was extracted with $3 \times 3 \mathrm{~mL}$ chloroform. The separated organic layer was dried over anhydrous sodium sulfate and transferred into a series of $10-\mathrm{mL}$ volumetric flasks then completed to volume with distilled water. The absorbance was measured against a blank solution which was treated under the same conditions at $576 \mathrm{~nm}$.

Stoichiometric studies: Job's method of continuous variation was employed. Master equimolar solutions $1.0 \times 10^{-5}$ $\mathrm{mol} / \mathrm{L}$ of Eriochrome black-T and ribavirin were prepared in methanol. A series of $10 \mathrm{~mL}$ of mixtures of the master solutions of the drug and Eriochrome black-T was prepared comprising different complementary proportions $(0: 10,1: 9 \ldots 9: 1,10: 0)$ in $15 \mathrm{~mL}$ volumetric flasks and the procedure mentioned above was followed. The absorbance of the resulting solutions was measured at $576 \mathrm{~nm}$ against a reagent blank treated similarly.

Analytical applications: The total content of ten capsules (Rebetol® $200 \mathrm{mg} /$ capsule) was mixed well. A weighed quantity of the powder equivalent to $15 \mathrm{mg}$ of ribavirin was transferred into a $100 \mathrm{~mL}$ volumetric flask, about $80 \mathrm{~mL}$ of distilled water was added and the flask was sonicated for 10 min. The solution was diluted to volume with distilled water, mixed and filtered. Serial dilutions covering the working concentration range of $2-120 \mu \mathrm{g} / \mathrm{mL}$ were transferred into $10 \mathrm{~mL}$ volumetric flasks. Procedure described above was then followed. The nominal content of the capsules was calculated using the calibration graph or the corresponding regression equation.

\section{RESULTS AND DISCUSSION}

The investigated anti-viral drug ribavirin contains an amino group which in acidic medium protonated and form with Eriochrome black-T an ion pair complex. The effect of acid type was studied using $1.5 \mathrm{~mL}$ of $5 \mathrm{~mol} / \mathrm{L}$ from each sulphuric acid, hydrochloric acid, perchloric acid, phosphoric acid, acetic acid and nitric acid. The calibration plots clarified that the highest absorbance and the most stable reading was obtained in the presence of $5 \mathrm{~mol} / \mathrm{L}$ acetic acid as shown in (Fig. 3).

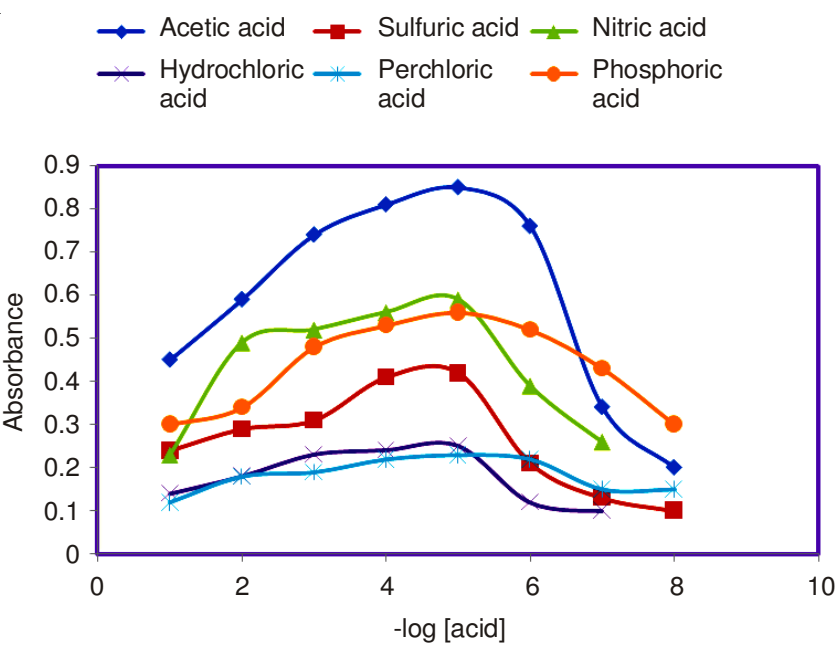

Fig. 3. Effect of acid type on absorption of ribavirin-Eriochrome black-T ion pair complex

Effect of acid concentration: The influence of acid concentration was investigated using different concentrations ranging from 1 to $10 \mathrm{~mol} / \mathrm{L}$. The procedure described above was followed and the obtained absorbance readings were plotted against acetic acid concentrations. Fig. 4 showed that the highest absorbance was achieved using $1.5 \mathrm{~mL}$ of $5 \mathrm{~mol} / \mathrm{L}$ acetic acid.

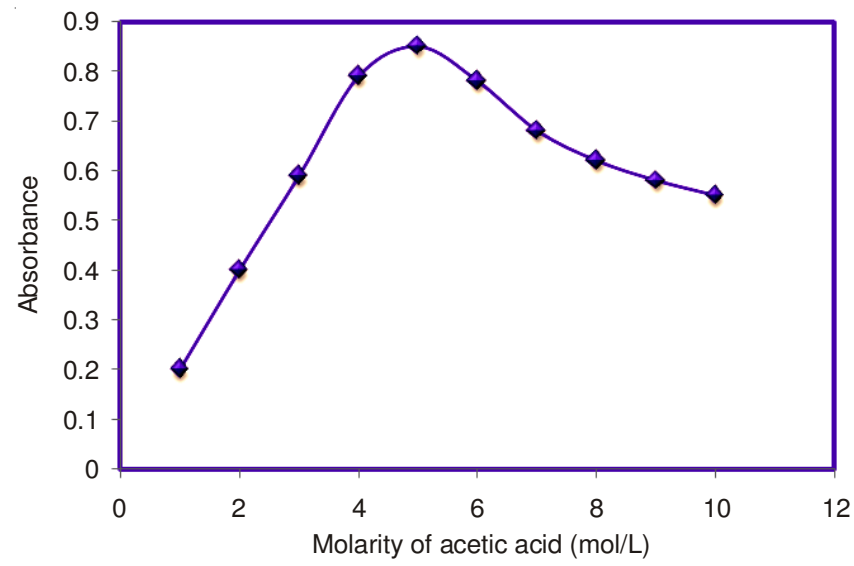

Fig. 4. Effect of acetic acid concentration on absorption of ribavirinEriochrome black-T ion pair complex 
Effect of acid volume: The effect of acid volume was studied using different volumes of acetic acid ranging from 0.5-3.0 mL. Fig. 5 showed that the highest absorbance was achieved using $1.5 \mathrm{~mL}$ of $5 \mathrm{~mol} / \mathrm{L}$ acetic acid.

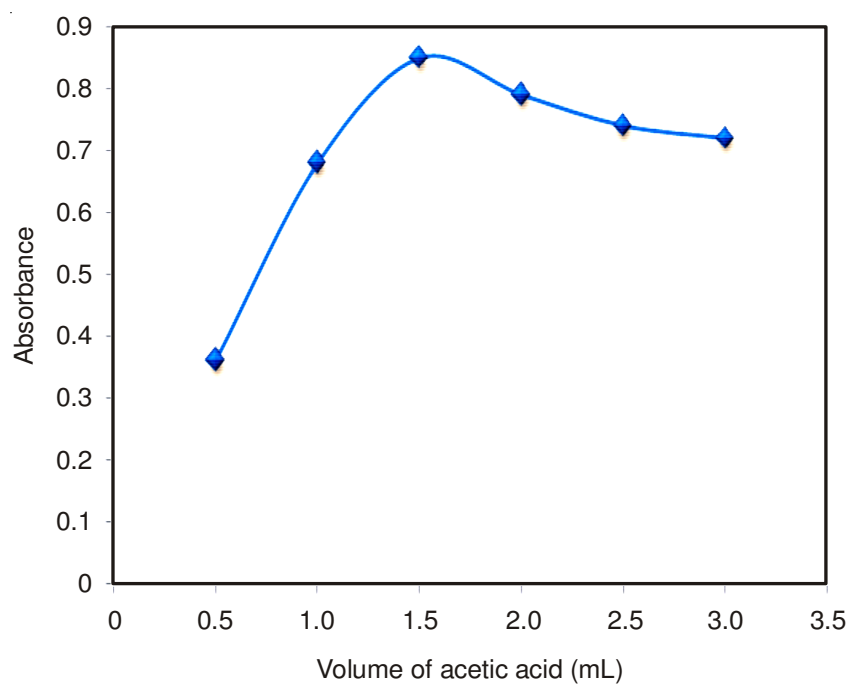

Fig. 5. Effect of acetic acid volume on absorption of $10 \mu \mathrm{g} / \mathrm{mL}$ ribavirinEriochrome black-T ion-pair complex

Effect of Eriochrome black-T concentration: Various concentration ranges (0.1-0.8) \% (w/v) of Eriochrome black-T were used to investigate its effect on the absorbance of the complex. The most preferred concentration which gave the highest absorbance value was found to be $0.2 \%$ as shown in Fig. 6 .

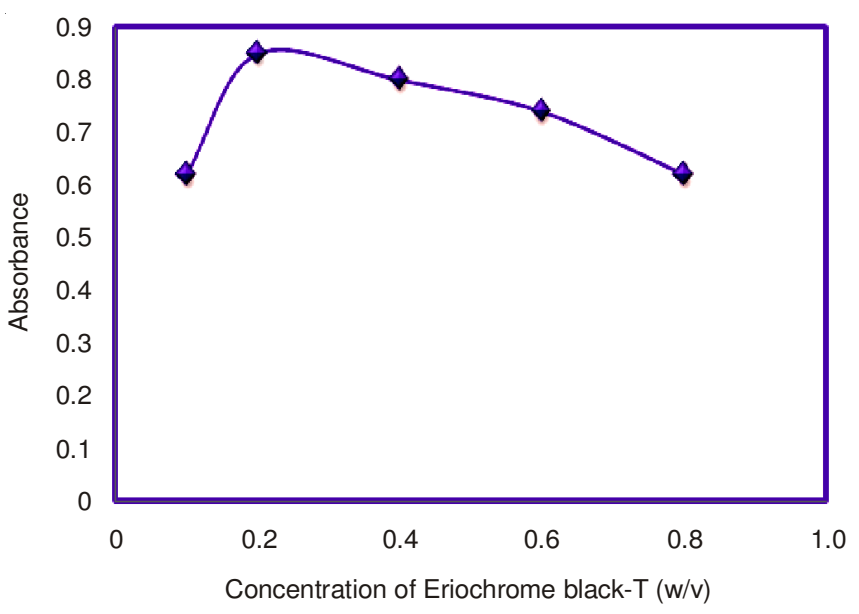

Fig. 6. Effect of Eriochrome black-T concentration (w/v) on absorption of $10 \mu \mathrm{g} / \mathrm{mL}$ ribavirin-Eriochrome black-T ion-pair complex

Effect of Eriochrome black-t volume: The influence of Eriochrome black-T volume was studied using various amounts $(0.2-1.0 \mathrm{~mL})$ of $0.2 \%(\mathrm{w} / \mathrm{v})$ solution. It was found that $0.5 \mathrm{~mL}$ is the most suitable volume of the reagent as shown in Fig. 7.

Effect of solvent type: In order to investigate the effect of solvent type on the efficiency and absorbance intensity, various kinds of solvents were used (chloroform, dichloromethane, 1,2- dichloroethane, benzene, toluene and ethyl acetate). The obtained results clarified that chloroform is the appropriate solvent for extraction of the studied drug. It was

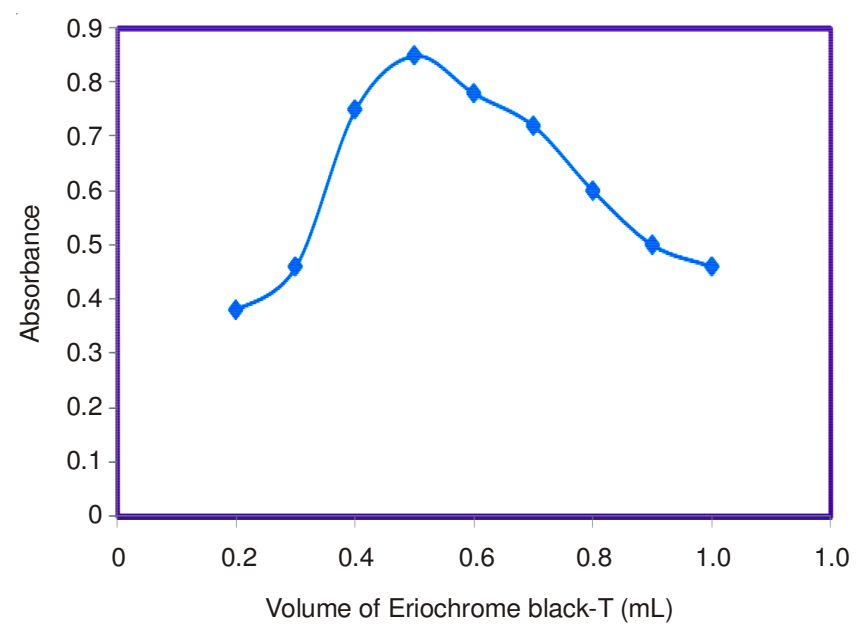

Fig. 7. Effect of Eriochrome black-T volume on absorption of $10 \mu \mathrm{g} / \mathrm{mL}$ ribavirin-Eriochrome black-T ion-pair complex

found that complete extraction was carried out using $3 \times 3 \mathrm{~mL}$ of chloroform and then complete to $10 \mathrm{~mL}$ with the same solvent.

Effect of the extraction time: The effect of extraction time on the ion-pair complex was examined. The drug-Eriochrome black-T complex was vigorously shacked for few minutes with the proper organic solvent (chloroform). It was found that $2 \mathrm{~min}$ is the optimum extracting time and the obtained colour was stable for at least $1 \mathrm{~h}$ at room temperature $\left(25 \pm 2{ }^{\circ} \mathrm{C}\right)$.

Stoichiometric ratio of the ion-pair complex: The stoichiometric ratio of the ion-pair formed between the drug under investigation and the reagent was investigated by applying the continuous variation method ${ }^{24}$ at the wavelength of maximum absorbance. The results obtained showed that the stoichiometric ratio of the ion-pair is 1:1 (reagent:ribavirin).

\section{Method validation}

Linearity, limit of detection and quantification: The standard calibration graph of ribavirin was constructed and the absorbance readings were plotted against the concentration of ribavirin. Under the optimal experimental conditions Beer's law was obeyed over a concentration range of $2-120 \mu \mathrm{g} / \mathrm{mL}$. The linear regression data and correlation coefficient were

\begin{tabular}{|c|c|}
\hline \multicolumn{2}{|c|}{$\begin{array}{c}\text { TABLE - } 1 \\
\text { CRITICAL RESPONSE CHARACTERISTICS OF RIBAVIRIN- } \\
\text { ERIOCHROME BLACK-T COMPLEX }\end{array}$} \\
\hline Parameter & Value \\
\hline$\lambda_{\max }(\mathrm{nm})$ & 576 \\
\hline Beer's Law limits $(\mu \mathrm{g} / \mathrm{mL})$ & $2.0-120.0$ \\
\hline Molarity of acetic acid (mol/L) & 5.0 \\
\hline Volume of acid (mL) & 1.5 \\
\hline Volume of Eriochrome black-T (mL) & 0.5 \\
\hline Concentration of eriochrome black-T (w/v) & 0.2 \\
\hline Extracting solvent & Chloroform \\
\hline *Regression equation & $\mathrm{A}=0.00376+0.00595 \mathrm{C}$ \\
\hline Correlation coefficient (r) & 0.999 \\
\hline $\mathrm{LOD}(\mu \mathrm{g} / \mathrm{mL})$ & 0.87 \\
\hline $\mathrm{LOQ}(\mu \mathrm{g} / \mathrm{mL})$ & 1.76 \\
\hline Sandell sensitivity $\left(\mu \mathrm{g} / \mathrm{cm}^{2}\right)$ & $3.4 \times 10^{-3}$ \\
\hline$\varepsilon\left(\times 10^{4}\right)(\mathrm{mol} / \mathrm{L} \mathrm{cm})$ & $9.3 \times 10^{-2}$ \\
\hline Robustness & $99.28 \pm 0.36$ \\
\hline
\end{tabular}


listed in Table-1. The lower limit of detection (LOD) and quantification (LOQ) were calculated according to $\mathrm{ICH}$ guidelines ${ }^{25}$. The results obtained were $0.87 \mu \mathrm{g} / \mathrm{mL}$ and $1.76 \mu \mathrm{g} / \mathrm{mL}$ respectively.

Robustness of the proposed method: The robustness of the proposed method was investigated by applying small variations of method variables such as concentration, volume of Eriochrome black-T and reaction time. The results obtained revealed that there is no significant difference between the results obtained by the proposed method and those after small variations (Table-1).

Sensitivity: Standard addition method was used to investigate the validity of the proposed method for the determination of ribavirin in its pharmaceutical dosage form. The results obtained in Table- 2 clarified high sensitivity of the proposed method for routine determination of ribavirin drug in its dosage form.

TABLE-2

ANALYTICAL APPLICATION OF STANDARD ADDITION TECHNIQUE FOR SPECTROPHOTOMETRIC DETERMINATION OF RIBAVIRIN DRUG IN ITS PURE AND DOSAGE FORMS

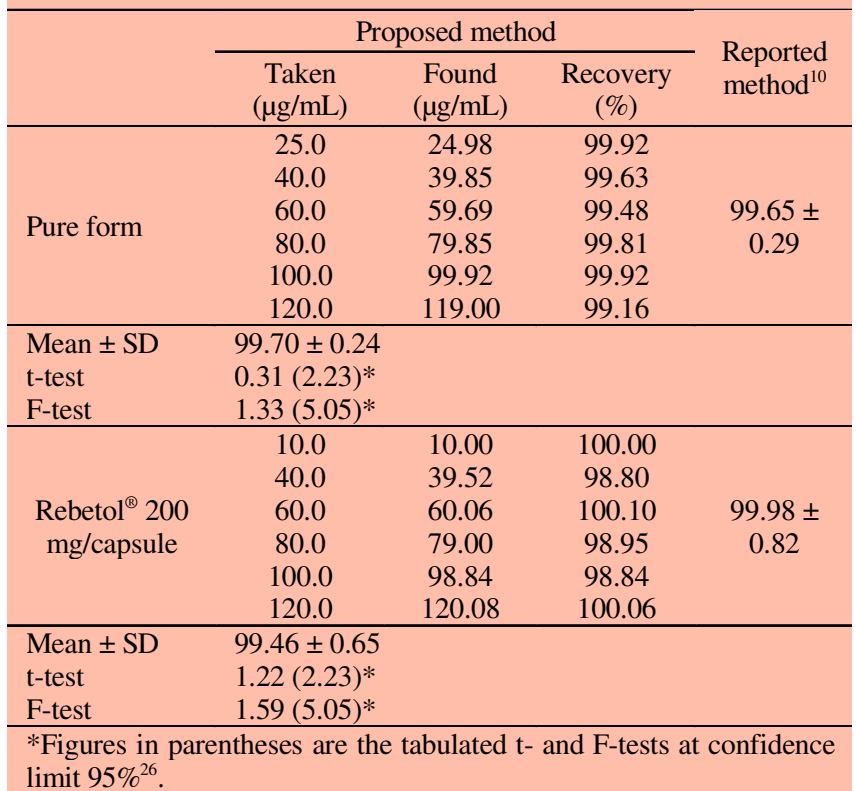

Accuracy and precision: Statistical analysis ${ }^{26}$ of the results obtained by the proposed and a reported spectrophotometric method ${ }^{10}$ (involves oxidation of ribavirin with cerium(IV) and the oxidative product is coupled with 3-methylbenzothiazolin 2-one hydrazone forming a deep blue colour which absorbs at $630 \mathrm{~nm}$ ) using student's t-test and variance ratio Ftest showed no significant differences between the two methods regarding accuracy and precision, respectively, (Table-2). The intra-day precision was evaluated by determination of six concentrations of ribavirin drug in pure form on three successive occasions. The inter-day precision was also evaluated through replicate analysis of six concentrations for a period of 3 successive days. The results of intra-day and inter-day precision are summarized in Table-3.

Analytical application: Under optimum conditions the proposed method was employed for determination of ribavirin in its pure form. The employed method exhibited high sensi-

\begin{tabular}{ccccc}
\multicolumn{5}{c}{ TABLE-3 } \\
\multicolumn{5}{c}{ VALIDATION OF THE PROPOSED METHOD FOR } \\
DETERMINATION OF RIBAVIRIN IN PURE FORM \\
\hline $\begin{array}{c}\text { Conc. } \\
(\mu \mathrm{g} / \mathrm{mL})\end{array}$ & $\begin{array}{c}\text { Found } \\
(\mu \mathrm{g} / \mathrm{mL})\end{array}$ & $\begin{array}{c}\text { Recovery } \\
(\%)\end{array}$ & $\%$ RSD & $\% \mathrm{SE}^{*}$ \\
\hline \multicolumn{5}{c}{ Intra-day precision } \\
\hline 5.0 & 4.99 & $99.80 \pm 0.4$ & 0.4 & 0.2 \\
10.0 & 9.95 & $99.50 \pm 0.2$ & 0.2 & 0.1 \\
50.0 & 49.65 & $99.30 \pm 0.6$ & 0.6 & 0.3 \\
100.0 & 99.80 & $99.80 \pm 1.2$ & 1.2 & 0.7 \\
120.0 & 119.78 & $99.82 \pm 0.8$ & 0.8 & 0.5 \\
\hline \multicolumn{5}{c}{ Inter-day precision } \\
\hline 5.0 & 4.98 & $99.60 \pm 1.4$ & 1.4 & 0.8 \\
10.0 & 9.95 & $99.50 \pm 0.9$ & 0.9 & 0.5 \\
50.0 & 49.59 & $99.18 \pm 0.4$ & 0.4 & 0.2 \\
100.0 & 99.96 & $99.96 \pm 1.2$ & 1.2 & 0.7 \\
120.0 & 119.58 & $99.65 \pm 0.5$ & 0.5 & 0.3 \\
\hline$* \% \mathrm{SE}=\mathrm{SD} / \sqrt{\mathrm{n}}$ & & &
\end{tabular}

tivity for the evaluation of the investigated drug and the results obtained were calculated as mean \% recoveries. As summarized in Table-2, the obtained result was $99.70 \pm 0.24$. Furthermore, the proposed assay was applied to the determination of ribavirin in a commercially available pharmaceutical Rebetol® which is labeled to contain $200 \mathrm{mg} / \mathrm{capsule}$. Rebetol was analyzed by the proposed procedure. The results obtained using standard addition method were statistically compared with those obtained by the published method ${ }^{10}$. The data in Table- 2 shows that the calculated $\mathrm{t}-$ and F-values are less than the tabulated ones, confirming accuracy and precision at $95 \%$ confidence limits ${ }^{26}$.

\section{Conclusion}

Simple extractive spectrophotometric method for the determination of ribavirin was developed. The proposed method besides its sensitivity and simplicity can be applied without elaborated treatment of samples. The method does not require expensive instruments or critical analytical reagents. These advantages gave the proposed method a great value and encourage its application to the analysis of ribavirin in quality control laboratories.

\section{ACKNOWLEDGEMENTS}

The authors extended their appreciation to the Deanship of Scientific Research at King Saud University for funding the work through the research group project No. RGP-VPP-062.

\section{REFERENCES}

1. L.J. Scott and C.M. Perry, Drugs, 62, 507 (2002).

2. M. Homma, A.L. Jayewardene, J. Gambertoglio and F. Aweeka, Antimicrob. Agents Chemother., 43, 2716 (1999).

3. A. Loregian, M.C. Scarpa, S. Pagni, S.G. Parisi and G. Palù, J. Chromatogr. B Analyt. Technol. Biomed. Life Sci., 856, 358 (2007).

4. L.-T. Yeh, M. Nguyen, S. Dadgostari, W. Bu and C.-C. Lin, J. Pharm. Biomed. Anal., 43, 1057 (2007).

5. W. Li, S. Luo, S. Li, L. Athill, A. Wu, T. Ray, W. Zhou, J. Ke, H.T. Smith and F.L.S. Tse, J. Chromatogr. B Analyt. Technol. Biomed. Life Sci., 846, 57 (2007).

6. M. Meléndez, O. Rosario, B. Zayas and J.F. Rodríguez, J. Pharm. Biomed. Anal., 49, 1233 (2009).

7. E. Zironi, T. Gazzotti, B. Lugoboni, A. Barbarossa, A. Scagliarini and G. Pagliuca, J. Pharm. Biomed. Anal., 54, 889 (2011). 
8. I.A. Darwish, H.F. Askal, A.S. Khedr and R.M. Mahmoud, J. Chromatogr. Sci., 46, 4 (2008).

9. M.C. Breadmore, R. Theurillat and W. Thormann, Electrophoresis, 25, 1615 (2004).

10. E.M.K. Sharaf, M.A. El-Brashy, S.Z. Awad and E.M. Rania, J. AOAC Int., 89, 631 (2006).

11. I.A. Darwish, K.S. Alaa, A.F. Hassan and M.M. Ramadan, J. AOAC Int., 89, 341 (2006).

12. N.A. Alarfaj and M.F. El-Tohamy, J. Indian Chem. Soc., 90, 1069 (2013).

13. N.A. Alarfaj and M.F. El-Tohamy, Luminescence, 28, 190 (2013).

14. I.A. Darwish, A.S. Khedr, H.F. Askal and R.M. Mahmoud, IL Farmaco, 60, 555 (2005)

15. D.P. Quan, D.P. Tuyen, T.D. Lam, P.T.N. Tram, N.H. Binh and P.H. Viet, Colloid. Surf. B, 88, 764 (2011).

16. A.E. Harvey, J.M. Komarmy and G.M. Wyatt, Anal. Chem., 25, 498 (1953).

17. J. Sulkowska, A. Budych and R. Stroscik, Chem. Anal., 30, 387 (1985).
18. D.B. Patil and D.M. Chafle, Asian J. Chem., 19, 3253 (2007).

19. B. Rajitha, S. Prashanthi, K.R. Ramsubha and G.R. Tulja, Int. J. Pharm. Tech. Res., 3, 114 (2011).

20. G.R. Tulja, S.D. Gowri, P. Kadgapathi, R. Suthakaran and B. Satyanarayana, Int. J. Pharm. Tech. Res., 2, 1787 (2010).

21. A.S. Amin, A.D. Hassan and A.A. Ibrahim, Arab. J. Chem., l, 209 (2008).

22. D.B. Patil and D.M. Chafle, Asian J. Chem., 19, 3253 (2007).

23. N. Rahman, N. Ahmad Khan and S.N. Hejaz Azmi, IL Farmaco, 59, 47 (2004).

24. J. Rose, Advanced Physico-Chemial Experiments, Pitman, London, p. 54 (1964).

25. ICH Technical Requirements for Registration of Pharmaceuticals for Human Use, Complementary Guidelines on Methodology, Washington, DC, vol. 13 (1996).

26. J.C. Miller and J.N. Miller, Statistics for Analytical Chemistry, Ellis Horwood-Prentice Hall, Chichester, edn 3 (1993). 